\title{
Blue-yellow colour vision in an onchocercal area of northern Nigeria
}

\author{
A Landers, I E Murdoch, J Birch, S N Cousens, O E Babalola, B Lawal, A Abiose, \\ B R Jones
}

Kaduna-London Collaboration for Research on Onchocerciasis, Institute of Ophthalmology, London EC1V 9EL A Landers I E Murdoch B R Jones

Department of Ophthalmology, Ahmadu Bello University Teaching Hospital, Kaduna, Nigeria

I E Murdoch

O E Babalola

A Abiose

Department of Optometry and Visual Science, City

University, London EC1V 7DD

J Birch

Department of Epidemiology and Population Sciences, London School of Hygiene and Tropical Medicine, London WC1E 7HT

$\mathrm{S}$ N Cousens

National Eye Centre, Kaduna, Nigeria B Lawal

A Abiose

Correspondence to: Ms Aideen Landers, International Centre for Eye Health, Institute of Ophthalmology, Bath Street, London EC1V 9EL.

Accepted for publication 6 November 1997

\begin{abstract}
Aim-To determine if the City University Tritan Test is a useful addition to visual function assessment in rural communities in northern Nigeria.

Methods-The study was a cross sectional survey. The participants were 8394 people, aged 5 years and over, living in 37 rural communities, mesoendemic and nonendemic for onchocerciasis, in Kaduna State in northern Nigeria. The main outcome measures were the detection of a defect in blue-yellow colour vision by two criteria: (1) failure with the City University tritan screening plates; (2) failure with the City University grading plates to identify severe tritan defects.

Results-91\% of those aged 10 years and above could perform the test. Below this age, there were difficulties in comprehension. The test showed good inter- and intraobserver agreement. After adjustment for confounders the odds of failing the screening plates were significantly increased in the presence of optic atrophy or glaucoma (3.55 (2.48-5.08) and 15.9 (4.22-60.2) respectively). There was a greater increase in the adjusted odds of failing the grading plates in the presence of optic atrophy or glaucoma (5.30 (2.979.45) and 8.87 (1.61-48.7) respectively). Cataract had a smaller effect on the screening plates, adjusted odds 1.63 (0.952.80).

Conclusion-Blue-yellow colour vision testing is a useful addition to visual function assessment in those aged 10 years and above in rural northern Nigeria, particularly in the detection of optic nerve disease.
\end{abstract}

(Br F Ophthalmol 1998;82:510-516)

Congenital tritan defects are rare. The prevalence of congenital tritanopia has been estimated as not greater than 1 in $13000 .{ }^{1}$ However, a survey of 1900 people by van Norren and Went, ${ }^{2}$ using a specially designed spectral instrument to measure short wavelength sensitivity, suggests that the frequency of congenital tritanomalous trichromatism may be as great as 2 per 1000 . Congenital tritan defects are inherited in an autosomal dominant pattern with almost complete penetrance. ${ }^{34}$ Unlike congenital red-green colour deficiency, phenotypical variations occur in tritan defects; some family members are dichromats and others are anomalous trichromats. ${ }^{5}$ Identification of congenital and acquired tritan defects with clinical tests, consisting of pigment colours, is complicated by individual variations in short wavelength sensitivity due to two yellow intraocular filters, the macular pigment, and the intraocular lens. Macular pigment density varies individually and remains constant throughout life. Changes in short wavelength sensitivity, owing to the transmissivity of the ocular lens, occur gradually with age ${ }^{6}$ and, in European populations, a significant deterioration in blue-green discrimination is found after about 55 years of age. ${ }^{7}$

Several studies have demonstrated acquired colour deficiency in individuals with ocular disease. Acquired tritan defects have been demonstrated in optic atrophy, ${ }^{8}$ glaucoma and ocular hypertension, ${ }^{9}$ and retinal degenerations including chorioretinitis, ${ }^{10}$ age related macular degeneration, and diabetic retinopathy. ${ }^{11}$ Colour vision tests are rarely available in rural African clinics. Therefore, the availability of a simple, cheap, and accurate test to detect tritan defects might be a worthwhile addition to the African ophthalmic nurse's or ophthalmologist's equipment, especially in onchocercal areas.

The City University Tritan Test has been shown to be useful for the detection of both congenital and acquired tritan defects in industrialised countries. ${ }^{412} 13$ Moreover, both congenital and acquired tritan defects have been shown to result in similar performance with tritan tests. ${ }^{8}{ }^{14}$

In a field trial to establish the efficacy of ivermectin for mass treatment of onchocerciasis in the guinea savannah of Kaduna State, northern Nigeria, 8394 people, aged 5 years and over, were examined for ocular disease. ${ }^{15}$ The ophthalmic examination was particularly concerned with identifying optic nerve disease. An early sign of optic nerve pathology is acquired type 3 (tritan) colour deficiency. ${ }^{89}$ The examination included assessment of blueyellow colour vision using the City University Tritan Test.

\section{Subjects and methods}

Two populations, one mesoendemic for onchocerciasis and one non-endemic for onchocerciasis, were examined. Those in the population mesoendemic for onchocerciasis participated in a trial of mass community treatment with ivermectin. ${ }^{15}$ The populations were demographically similar. The populations underwent a census. ${ }^{15} 16$ Informed consent to participate in the study was obtained after full explanation of the purpose of the investigation. Individuals were registered and photographed. 
Eighty seven per cent of the censused population aged 5 years and above took part in the study-6831 people from 34 communities which were mesoendemic for onchocerciasis and 1563 people from three non-endemic communities were examined, giving a total of 8394 participants examined.

Each participant underwent an extensive ophthalmic screening examination (including the City University Tritan Test) which was performed at a central location in each village, during 1989 to 1991 . The examinations were carried out by a team of six trained ophthalmic nurses who showed good interobserver agreement for the tests employed. ${ }^{16}$ The visual function assessment included visual fields and the examination included intraocular pressures and ophthalmoscopy. Individuals were referred to the ophthalmologists for examination if ocular pathology was found or suspected. One of the indications for referral was an isolated tritan defect. In addition, a random sample of all participants underwent examination by the two ophthalmologists and completed all the tests under their supervision. There were 773 individuals in this sample. ${ }^{17}$

The City University Tritan Test was performed in photopic conditions under open canvas in diffuse daylight. The nurse explained the test to the subject in a local language. The test consists of five plates mounted on black card, and three practice plates. A detailed description is given in the appendix. The plates are pseudoisochromatic "vanishing" designs in which the contained figure is a simple geometric shape. Each plate has a background dot pattern with one of four possible shapes superimposed (Figs 2 and 3) The only distinction between background and shape is colour wavelength. Two colour difference steps are employed. The three screening plates have small colour differences and were designed for the detection of tritan defects (tritanomalous trichromatism). The two grading plates have large colour difference steps designed for the identification of severe colour deficiency (tritanopia). ${ }^{18}$ The hidden geometric shape may be a triangle, circle, square, or a cross. None of the shapes in any of the plates can be seen by a congenital tritanope. Each plate is oblong and the test shape is offset to the right or left end (see Appendix 1). On the page opposite each plate there was a black and white control diagram with all four shapes illustrated so the subject could indicate which shape was represented in the colour plate. The participant would indicate at which end of the plate the shape was located and say which shape was represented. If the subject had poorer comprehension, they were asked to trace the colour plate shape on the symbol itself. Right and left eyes were tested separately. The shapes within the plates are large in size. Subjects with visual acuities of $6 / 60$ and better are able to see the shapes. Subjects whose visual acuity in the better eye was $3 / 60$ or worse, however, were excluded from the analysis. Inability to perform the tritan test through lack of comprehension was judged by the examining nurses, when the subject was tested looking at the black and white control. The term "inability to perform the test" as used below and in the Results section, refers to the subject's poor understanding of the test, and is not referring to the presence of ocular pathology rendering the subject unable to see the shapes. However this assumes no, or negligible, miscoding by the examining nurses.

Failing the screening plates was defined as the subject being unable to see two or more of the three plates. Failing the grading plates, and hence the presence of a severe tritan defect, was defined as failing two or more of the screening plates and one or more of the grading plates.

\section{DATA ANALYSIS}

The data were entered onto a microcomputer using a double entry method and subsequently cleaned, including the use of internal validation checks. Multiple logistic regression was used to determine adjusted odds ratios for failure according to the specified criteria (as defined above). In order to investigate risk factors for failing the tritan test, three groups of variables were investigated. The first concerned social and demographic variables such as ethnic group, religion, sex, occupation, and education. The second group concerned individual factors that may be associated with increased risk of failing the tritan test, including onchocerciasis infection and alcohol and diethylcarbamazine consumption. The third and final group of variables were those related to ocular pathology that may affect the likelihood of passing the tritan test such as visual acuity, cataract, and optic nerve pathology. Each variable was investigated individually and in more complex models for risk factors for test failure.

INTER AND INTRA-INVESTIGATOR VARIATION

Two trials were performed to investigate interobserver variation in which three groups of 12 eyes were tested by nurse pairs for each of the eight colour plates (five test plates plus three practice plates), making a total of 288 paired comparisons. In the first trial there were 32 disagreements. Retraining was undertaken and the trial repeated with only two disagreements between nurses. In both trials approximately one third of eyes tested had abnormalities. Intraobserver variation was tested with paired comparisons in 76 individuals using the five tritan test plates-that is, the three screening plates and the two grading plates. Ninety seven per cent of the 152 eyes tested twice resulted in consistent answers.

\section{Results}

The ability of children to perform the City University Tritan Test - that is, their comprehension of the test, increased with age to 10 years. After the age of 30 years there was a decline in ability to perform the test. Figure 1 illustrates the proportion of individuals unable to perform the test by age.

Failure with the grading plates should not occur without failure with the screening plates, and indeed this proved so with only $0.1 \%$ of all eyes giving aberrant results. 


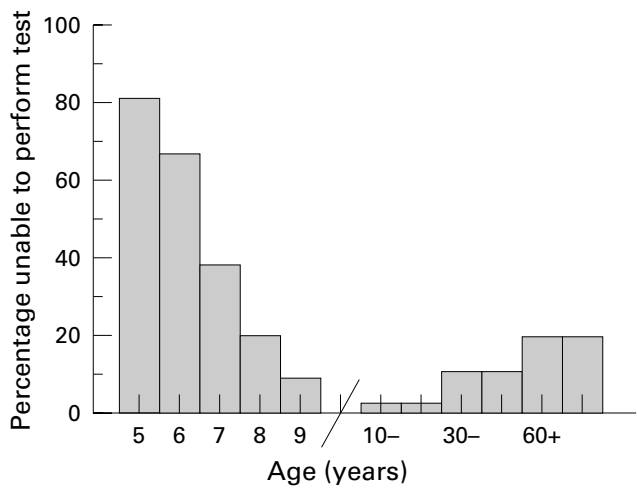

Figure 1 Histogram of ability to perform the City University Tritan Test by age in an onchocercal area, northern Nigeria.

Of the 8394 individuals examined, 474 failed the screening plate tests in both eyes. There were two groups of participants, those with no ophthalmic abnormality diagnosed in either eye, on the basis of the nurses' findings, and those with an abnormality detected. Altogether, 4830 (58\%) participants had no abnormality detected in either eye and, of these, 111 (2.3\% of this group) failed the screening plates in one eye and a further $62(1.3 \%)$ failed it in both eyes. This failure was equally distributed among males and females but was more common in those with positive skin snips for microfilariae, compared with those with negative snips. There were 2875 individuals within this group with no ocular abnormality diagnosed in either eye, who also had negative skin snips. Of these, 2125 were able to perform the test; 23 of these failed the screening plates in both eyes, giving a conservative estimate of $0.8 \%$ prevalence for slight tritan defects. No individual in this group failed the grading plates bilaterally. A total of $3564(42 \%)$ participants were in the second group who had an abnormality diagnosed in either eye. Of these, 341 (9.6\% of this group) failed the screening plates in one eye and a further 412 $(11.6 \%)$ individuals failed the screening plates in both eyes.

RISK FACTORS FOR FAILING THE CITY UNIVERSITY TRITAN TEST

After exclusion of individuals for whom there were no test results recorded, crude odds ratios were calculated for failing the tritan screening plates according to the various variables which may have had an effect. These are given in Tables 1 and 2 .

As can be seen in Table 2 eyes with optic nerve disease, particularly glaucoma had the highest odds ratio for failing the City University Tritan Test, by either criteria. Other important associations with failure were increased age and cataract. A small increase in odds for failing the screening plates, but not the grading plates, was seen in those who reported any past or present alcohol consumption.

\section{VISUAL ACUITY}

Visual acuity had a profound effect on whether a subject passed or failed the test. Not surprisingly, this was most marked for acuities of 3/60 or worse. As was mentioned in the Methods section, subjects with a visual acuity of $3 / 60$ or worse in the better eye were then excluded from the analysis. We have also described how the shapes within the plates are large and subjects with visual acuities of $6 / 60$ and better were able to see the shapes. However, the results of logistic regression, which was performed for failure with the screening plates and for failure with the grading plates, even after restriction to those with acuities of $3 / 60$ or

Table 1 Crude and adjusted odds ratios (right eyes) for failing City University Tritan Test in an onchocercal area, northern Nigeria, according to the two sets of criteria. Social variables that may affect test result

\begin{tabular}{|c|c|c|c|c|}
\hline \multirow[b]{2}{*}{ Variable under comparison } & \multicolumn{2}{|c|}{ Relative odds of failing screening plates ( $95 \%$ CI) } & \multicolumn{2}{|c|}{ Relative odds of failing grading plates ( $95 \% \mathrm{CI})$} \\
\hline & Crude odds ratio & Adjusted odds ratio & Crude odds ratio & Adjusted odds ratio \\
\hline \multicolumn{5}{|l|}{ Sex: } \\
\hline Female & 1 & 1 & 1 & 1 \\
\hline Male & $0.92(0.74-1.13)$ & $0.91(0.69-1.22)$ & $1.04(0.69-1.57)$ & $1.30(0.72-2.32)$ \\
\hline \multicolumn{5}{|l|}{ Age (years): } \\
\hline $5-15$ & 1.00 & 1.00 & 1.00 & 1.00 \\
\hline $16-25$ & $0.69(0.43-1.12)$ & $0.62(0.35-1.09)$ & $9.94(1.20-82.7)$ & $6.80(0.72-64.5)$ \\
\hline $26-35$ & $2.68(1.86-3.85)$ & $2.11(1.30-3.43)$ & $35.0(4.61-265)$ & $23.9(2.87-200)$ \\
\hline $36-45$ & $5.21(3.68-7.36)$ & $3.15(1.92-5.17)$ & $87.0(11.8-642)$ & $34.6(4.11-290)$ \\
\hline $46-55$ & $9.39(6.51-13.6)$ & $4.96(2.92-8.41)$ & $148(20-1104)$ & $46.6(5.42-401)$ \\
\hline $56+$ & $15.7(10.9-22.6)$ & $5.14(2.87-9.21)$ & $224(30-1661)$ & $29.7(3.26-270)$ \\
\hline \multicolumn{5}{|l|}{ Ethnic group: } \\
\hline Hausa & 1.00 & 1.00 & 1.00 & 1 \\
\hline Kurama & $1.85(1.29-2.66)$ & $0.82(0.37-1.80)$ & $2.52(1.11-5.73)$ & $1.31(0.30-5.66)$ \\
\hline Gure/Kahugu & $3.06(2.14-4.37)$ & $1.47(0.65-3.33)$ & $5.61(2.64-11.9)$ & $2.64(0.59-11.8)$ \\
\hline Other & $2.07(1.56-2.73)$ & $1.32(0.62-2.81)$ & $3.52(1.83-6.75)$ & $3.62(0.89-14.7)$ \\
\hline \multicolumn{5}{|l|}{ Education: } \\
\hline None & 1.00 & 1.00 & 1.00 & 1.00 \\
\hline Primary/Koranic school & $0.31(0.24-0.40)$ & $1.03(0.72-1.47)$ & $0.13(0.07-0.23)$ & $0.63(0.28-1.43)$ \\
\hline Secondary/higher & $0.38(0.25-0.57)$ & $0.66(0.41-1.08)$ & $0.24(0.10-0.60)$ & $0.36(0.13-1.00)$ \\
\hline \multicolumn{5}{|l|}{ Occupation: } \\
\hline Farmer & 1.00 & 1.00 & 1.00 & 1.00 \\
\hline Fisher/hunter part/full time & $1.32(0.87-2.00)$ & $0.84(0.50-1.41)$ & $1.37(0.64-2.93)$ & $0.79(0.30-2.07)$ \\
\hline Retired & $5.33(3.14-9.03)$ & $1.86(0.92-3.77)$ & $5.49(2.40-12.6)$ & $2.36(0.73-7.68)$ \\
\hline Other & $0.53(0.43-0.67)$ & $1.09(0.80-1.49)$ & $0.41(0.26-0.65)$ & $1.59(0.89-2.84)$ \\
\hline \multicolumn{5}{|l|}{ Religion: } \\
\hline Moslem & 1.00 & 1.00 & 1.00 & 1.00 \\
\hline Christian & $1.77(1.36-2.30)$ & $1.35(0.67-2.74)$ & $2.46(1.38-4.37)$ & $1.25(0.39-4.01)$ \\
\hline Traditional & $5.07(3.49-7.36)$ & $1.21(0.56-2.65)$ & $7.08(3.38-14.8)$ & $0.70(0.19-2.63)$ \\
\hline
\end{tabular}

Adjustment for sex, age, ethnic group, education, occupation, religion, alcohol and diethylcarbamazine consumption, microfilarial load, visual acuity, and diagnosis of cataract and optic nerve disease. Results from right eyes only presented, since there was no statistical difference from the left eye results. 
Table 2 Crude and adjusted odds ratios (right eyes) for failing the City University Tritan Test in rural communities in an onchocercal area, northern Nigeria, according to two criteria. Variables investigating factors toxic to optic nerve and ocular disease

\begin{tabular}{|c|c|c|c|c|}
\hline \multirow[b]{2}{*}{ Variable under comparison } & \multicolumn{2}{|c|}{ Relative odds of failing screening plates ( $95 \%$ CI) } & \multicolumn{2}{|c|}{ Relative odds of failing grading plates ( $95 \%$ CI) } \\
\hline & Crude odds ratio & Adjusted odds ratio & Crude odds ratio & Adjusted odds ratio \\
\hline \multicolumn{5}{|l|}{ Alcohol: } \\
\hline Never & 1.00 & 1.00 & 1.00 & 1.00 \\
\hline Drink past/present & $2.48(2.00-3.08)$ & $1.39(0.99-1.96)$ & $2.94(1.90-4.55)$ & $0.90(0.46-1.77)$ \\
\hline \multicolumn{5}{|l|}{ Diethylcarbamazine: } \\
\hline Never & 1.00 & 1.00 & 1.00 & 1.00 \\
\hline Yes & $3.08(2.48-3.82)$ & $1.07(0.80-1.44)$ & $4.86(3.21-7.36)$ & $1.14(0.66-1.96)$ \\
\hline \multicolumn{5}{|l|}{ Skin snip: } \\
\hline Negative & 1.00 & 1.00 & 1.00 & 1.00 \\
\hline Microfilaria positive & $2.59(2.09-3.21)$ & $1.22(0.90-1.65)$ & $4.64(2.89-7.44)$ & $1.14(0.62-2.10)$ \\
\hline \multicolumn{5}{|l|}{ Visual acuity: } \\
\hline $6 / 9$ & 1.00 & 1.00 & 1.00 & 1.00 \\
\hline $6 / 18-6 / 60$ & $13.8 \quad(10.5-18.2)$ & $3.35(2.29-4.90)$ & $29.4 \quad(19.1-45.4)$ & $7.88(4.35-14.3)$ \\
\hline \multicolumn{5}{|l|}{ Diagnosis of cataract } \\
\hline None & 1.00 & 1.00 & 1.00 & 1.00 \\
\hline Yes & $11.1(7.61-16.1)$ & $1.63(0.95-2.80)$ & $10.17(5.60-18.5)$ & $1.27(0.52-3.08)$ \\
\hline \multicolumn{5}{|c|}{ Diagnosis, optic nerve disease } \\
\hline None & 1.00 & 1.00 & 1.00 & 1.00 \\
\hline Optic atrophy & $9.68(7.34-12.8)$ & $3.55(2.48-5.08)$ & $24.1 \quad(15.7-37.2)$ & $5.30(2.97-9.45)$ \\
\hline Glaucoma & $29.0 \quad(10.7-78.4)$ & $15.9(4.22-60.2)$ & $46.8(14.6-150)$ & $8.87(1.61-48.7)$ \\
\hline
\end{tabular}

Adjustment for sex, age, ethnic group, education, occupation, religion, alcohol, and diethylcarbamazine consumption, microfilarial load, visual acuity, and diagnosis of cataract and optic nerve disease. Results from right eyes only presented, since there was no statistical difference from the left eye results.

better, show that visual acuity still had an effect. This restriction was maintained for all other analyses. The resultant odds ratios for failing the screening plates and for failing the grading plates are also given in Table 1, under the heading "Adjusted odds ratio".

AGE

The odds of failing the test increased with age even after correction for visual acuity and eye pathology.

DIETHYLCARBAMAZINE

The previously used microfilaricide, diethylcarbamazine, is known to precipitate and aggravate onchocercal optic nerve disease. ${ }^{19}$ The crude odds ratio suggested a 3.82 increased odds of failing the screening plates in those who had taken diethylcarbamazine at some stage in the past. Controlling for area, optic nerve disease, alcohol consumption, or education had no marked effect on this association. However, correcting for age resulted in a substantial reduction of this odds ratio close to unity.

ONCHOCERCAL INFECTION

Individuals with positive skin snips had an increased risk of tritan defects as detected by either the screening plates or the grading plates. After adjustment for confounders, the association was no longer statistically significant. Analysis using microfilarial $(\mathrm{mf})$ count as a categorical variable showed those with skin snips containing greater than $10 \mathrm{mf} / \mathrm{mg}$ skin to have a greater risk of failing the screening plates after adjustment for confounders (Table 3).

SEX

Males had a crude odds ratio of 1.2 for failing the screening plates compared with females. After adjusting for the increased prevalence of optic nerve disease among men there was no evidence of a difference between the results for men and women.

ETHNIC GROUP AND RELIGION

The Hausas had an apparently lower odds of failing the screening plates than any of the other ethnic groups. Virtually all Hausas gave their religion as Muslim; however, controlling for religion did not remove the effect of ethnic group. When alcohol consumption, past or present, was considered the effect of ethnic group was mostly removed. Those who reported Muslim faith appeared to have the least odds of failing the screening plates. Controlling for ethnic group alone reduced the odds ratio for Christians and the addition of correction for visual acuity reduced the association for traditional beliefs. In the final model this apparent association completely disappeared as a result of small contributions by the other factors.

OCCUPATION

Controlling for age removed all apparent associations between occupation categories and failure of the screening plates, except for those

Table 3 Crude and adjusted odds of failing the City University Tritan Test by degree of skin snip positivity, in an onchocercal area, northern Nigeria

\begin{tabular}{|c|c|c|c|c|}
\hline \multirow[b]{2}{*}{$\begin{array}{l}\text { Skin snip } \\
\text { (mf/mg skin) }\end{array}$} & \multicolumn{2}{|l|}{ Screening plates } & \multicolumn{2}{|l|}{ Grading plates } \\
\hline & $\begin{array}{l}\text { Crude odds } \\
(95 \% \text { CI) }\end{array}$ & $\begin{array}{l}\text { Adjusted odds } \\
(95 \% \text { CI })\end{array}$ & $\begin{array}{l}\text { Crude odds } \\
(95 \% \text { CI })\end{array}$ & $\begin{array}{l}\text { Adjusted odds } \\
(95 \% \text { CI })\end{array}$ \\
\hline Negative & 1.00 & 1.00 & 1.00 & 1.00 \\
\hline $1-10$ & $2.36(1.94-2.86)$ & $0.98(0.70-1.39)$ & $3.18(2.47-4.10)$ & $0.92(0.46-1.83)$ \\
\hline $11-50$ & $3.63(2.94-4.47)$ & $1.52(1.05-2.20)$ & $4.76(3.63-6.24)$ & $1.46(0.72-2.95)$ \\
\hline $51+$ & $4.20(3.10-5.70)$ & $1.90(1.15-3.14)$ & $4.83(3.28-7.12)$ & $1.71(0.68-4.28)$ \\
\hline
\end{tabular}

Adjustment after restriction to those with visual acuities of better than 3/60 for sex, age, ethnic group, education, occupation, religion, alcohol and diethylcarbamazine consumption, visual acuity, and diagnosis of cataract and optic nerve disease. 
who reported retirement. After controlling for visual acuity this association was no longer statistically significant. However, in the full model the retired group still had a small increased odds of failing the screening plates but not the grading plates.

RIGHT OR LEFT EYES

Tritan test results for right and left eyes were highly correlated (screening plates $94.6 \%$ concordance, grading plates $98.4 \%$ concordance). Thus no important loss in the precision of the odds ratio results from the use of right eye results only as opposed to an analysis using the complete data set with correction for between eyes correlation. ${ }^{20}$

\section{Discussion}

The City University Tritan Test has been designed to be appropriate for all ages, including preschool children, and to be comprehensible for people who have had limited educational opportunities. The test proved easy to explain and acceptable to the villagers, taking an average of 3 minutes to perform. It was interesting that the under 10 year olds fared badly. This could be for a variety of reasons. Hausa is the main language of the region and the test was explained in Hausa. It could be postulated that use of their second language to explain the test placed children whose ethnic group was not Hausa at a disadvantage. Examination of age and ethnic group as specific risks of inability to understand the test, however, showed that there was a similar pattern across all ethnic groups. Thus, the Hausa children did not have an advantage. Another explanation may be cultural differences. In the United Kingdom we have observed that a cross is the most difficult shape for children to recognise among the shapes employed. Geometrical shapes may be less familiar to African children in a rural community. However, $98 \%$ of teenagers, and $91 \%$ of all those aged 10 years and over, could perform the test. Thus the adaptation of the test to include familiar objects such as animal shapes or houses may be appropriate for those aged under 10 years. The apparent benefit of schooling is largely due to the younger age structure of this population. A beneficial effect for passing the test persists, however, for secondary or higher education even after correction for age and the other risk factors. This could be due to a further increase in comprehension of the test itself in this group, or it is possible that the test is detecting preclinical optic nerve disease and those not undertaking secondary education are more at risk of this. In a case-control study, over $50 \%$ of optic nerve disease in the communities examined was estimated to be attributable to onchocercal infection. ${ }^{21}$ Those children who were working in the fields, rather than going to school, would be more at risk of onchocerciasis.

The odds ratios confirm that optic nerve pathology, particularly glaucoma, is associated with tritan defects. ${ }^{89}$ While the confidence intervals (Table 2 ) overlap between the relative odds for failing the test in individuals with optic nerve atrophy compared with those with glaucoma, there is a consistent trend for higher odds for failure in those with glaucoma. A possible explanation for the difference in relative odds for failing the tritan test between optic nerve disease and glaucoma could be that the nature of optic nerve damage differs between the two diseases, glaucoma preferentially causing tritan defects. ${ }^{9}$

Cataract is known to affect blue-yellow perception since the lens absorbs short wavelength (blue) light. $^{22}$ This occurs naturally with increasing age and is more particularly the case with nuclear sclerosis than with cortical opacities. It was of interest to note that cataract had a small effect on the adjusted odds ratio for failing the screening plates.

The association of increasing age with increased odds of failing the tritan test could well be due to an increasing prevalence of other ocular pathology in this group-for example, onchocercal chorioretinal and neuroretinal disease.

A history of past or present consumption of alcohol (locally brewed beer) was associated with an increased odds of failing the tritan test. Some of this was due to confounding by age and optic nerve disease together. A small effect persisted for failure with the screening plates in the full model but not for failure with the grading plates. This inconsistency suggests the finding for the screening plates is likely to be a chance finding. However, the possibility that alcohol consumption might result in blueyellow colour vision defects has been raised in the past, with conflicting opinions being expressed. ${ }^{23} 24$

Among the individuals with negative skin snips for onchocerciasis and no abnormal ocular finding in either eye, we found that $0.8 \%$ of the population failed the tritan screening plates in both eyes. No one was found to fail the grading plates in both eyes. This figure cannot be taken to represent the prevalence of congenital tritan defects, because none of the figures in the screening or the grading plates can be seen by a congenital tritanope. It would also be unusually high. ${ }^{12}$ It could be assumed that congenital tritan defects would be expected to be bilateral, and equal in severity, and if a monocular tritan defect is detected then it is more likely to be acquired. However, if the figure of $0.8 \%$ for the prevalence of slight tritan defects were representing congenital tritan defects, then the same number should have failed the grading plates. There are three possible explanations for our prevalence figure of $0.8 \%$ for slight tritan defects. Either this number represents false positives, or it could represent some acquired subclinical tritan defectives, or it may represent a combination of the first two. Onchocercal chorioretinitis was only investigated in those undergoing full examination by the ophthalmologists. Addition of presence or absence of chorioretinitis to the analytical model was non-contributory. However, interestingly, cross tabulation of those with clinically normal optic discs showed a higher percentage of those that failed the screening plates or the grading plates had 


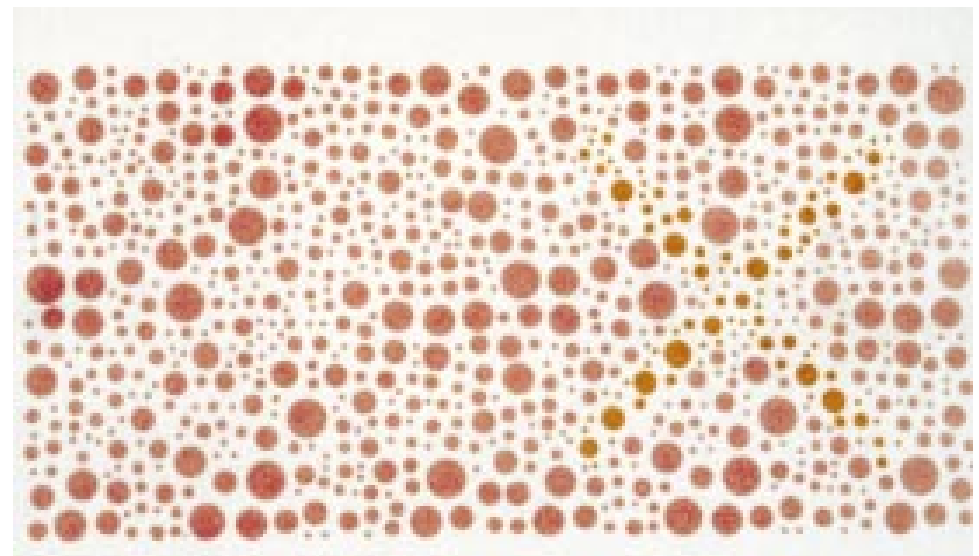

Figure 2 Screening plate for detection of tritan defect.

onchocercal chorioretinitis (confirmed by fluorescein angiography).

It is thus possible that the City University Tritan Test is able to detect very early disease. This could make it very useful as an early screening test for optic nerve pathology. Because of individual variations in threshold blue perception, pseudoisochromatic designs for tritans have low specificity if the colour difference step between the figure and the background is too small, and low sensitivity if the colour difference step is too large. In the investigation of congenital tritans by Went and Pronk $^{4}$ the City University Tritan Test, used in this study, was shown to be more reliable for detecting tritans than other readily available clinical tests such as the HRR and F2 plates, the Farnsworth D15 (saturated and desaturated) and the Farnsworth-Munsell 100 hue test. (A more recent plate test, the Lanthony Tritan Album, has been shown to have low sensitivity in identifying type 3 (tritan) defects in diabetic retinopathy ${ }^{25}$ and in glaucoma. ${ }^{26}$ )

This prevalence figure for slight tritan defects, and the possible associations with alcohol consumption and increasing age, and the protective effect of schooling (see Table 1) could all be explained by residual confounding

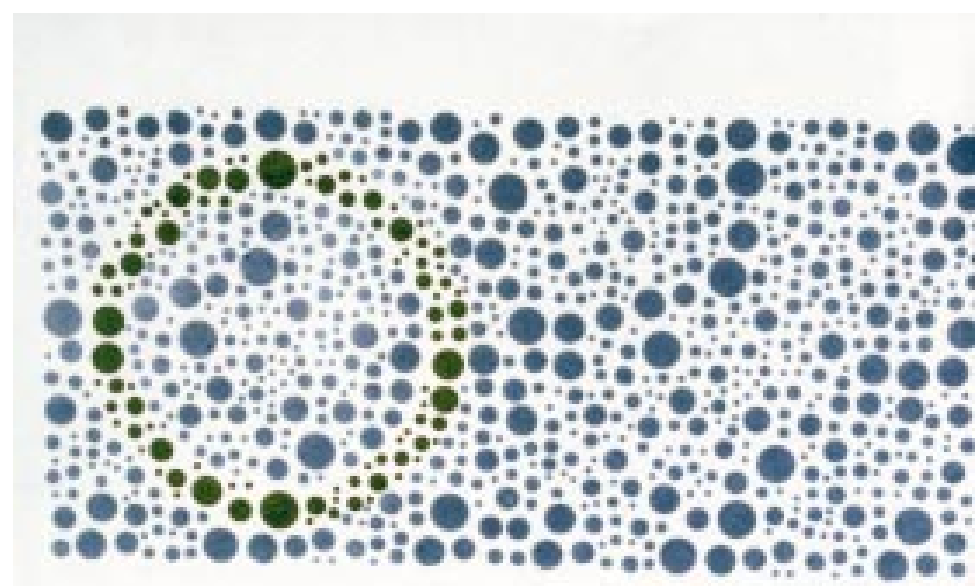

Figure 3 Grading plate to identify severe tritan defects. from subclinical pathology-for example, preclinical optic nerve changes, increased lens density, or preclinical retinal changes.

The City University Tritan Test was part of a battery of tests in the formal ophthalmic examination of the communities. The sensitivity of the screening plates alone for probable or definite optic nerve disease (as defined in our earlier paper ${ }^{21}$ and in appendix 2) in an individual was $35 \%$, and the specificity $97 \%$. For the grading plates, the sensitivity was $55 \%$ and the specificity $92 \%$. This compared favourably with other visual function tests. ${ }^{27}$

The results of this study show the City University Tritan Test to be a practical and useful addition to the assessment of visual function in rural communities in northern Nigeria. Although, in isolation, a colour vision defect has little functional significance, we propose that this test could be used as a screening test for early optic nerve disease by ophthalmic nurses and ophthalmologists in rural communities.

\section{Appendix 1: The City University Tritan Test}

The City University Tritan Test has five pseudoisochromatic plates for the detection and evaluation of congenital tritan defects and acquired type 3 (tritan) defects. ${ }^{28}{ }^{29}$ The test design is similar to that of the American Optical Company (Hardy, Rand, and Rittler) plates (A-O HRR), and provides both screening and an estimate of severity. All the plates have "vanishing" designs in which the contained figure is a geometric shape. The figure may be a circle, cross, square, or triangle and is positioned either on the right or on the left of a rectangular dot matrix which forms the background to the plate. The background dot matrix and the dots which compose the figure are printed in single colours. There are two levels of severity. Three plates have small colour differences and are for identifying tritan defects (the screening plates). Two plates are have larger colour differences and are for identifying severe tritan defects (the grading plates). People who fail to see the figure in the screening plates only have slight tritan colour deficiency and those who fail both screening and grading plates have a severe tritan defect.

The chromaticity coordinates of each pair of colours are within isochromatic zones for congenital tritanopia and none of the figures can be seen by a congenital tritanope. The screening plates contain desaturated reds and red purples (Fig 2) and the grading plates have blue/green and violet/yellow-green colour pairs (Fig 3). The colour differences are between 30 and 40 CIELab units for the three screening plates and between 70 and 90 units for the two grading plates. The prototype test has been evaluated in two independent surveys to determine the prevalence of congenital tritan colour deficiency. ${ }^{2}$ The test successfully identified 28 of 31 people shown to be tritan by psychophysical tests compared with 18 people identified by the tritan plates of the A-O (HRR) plates and the Farnsworth F2 plate. ${ }^{4}$ The prototype test is also effective in identifying and evaluating acquired type 3 (tritan) defects in 
patients with diabetic retinopathy. ${ }^{13}$ No errors are made by people with normal colour vision under 55 years of age. Errors on plate 1 which has the smallest colour difference, tend to increase progressively after 55 years of age owing to physiological changes in the transmissivity of the ocular lens.

\section{Appendix 2: Definition of optic nerve disease}

DEFINITE OPTIC NERVE DISEASE

Either marked disc pallor recorded by an ophthalmologist together with defects in visual function and/or pupillary light response

or active optic neuritis confirmed by fluorescein angiography.

PROBABLE OPTIC NERVE DISEASE

Either an eye with no perception of light, with no view of the disc, and no history or other ocular pathology to account for this visual acuity

or an afferent pupillary defect identified by an ophthalmologist, with no view of the disc and no history or other ocular pathology to account for the finding

or mild or moderate disc pallor recorded by an ophthalmologist in association with recorded defects in visual function or an afferent pupillary defect

or disc pallor recorded by an ophthalmic nurse, disc not seen by an ophthalmologist, with three or more visual function tests failed ${ }^{15}$ or an afferent pupillary defect.

We thank the Luton and Dunstable Eye Department for releasing Aideen Landers to undertake this work. The authors ing Aideen Landers to undertake this work. The authors warmly acknowledge the ophthalmic nurses Iyabo Bolarin, Ibrahim Liman, Peter Danboyi, Joyce Onyema, Dauda Jatau, for their untiring work throughout the duration of the trial. The for their untiring work throughout the duration of the trial. The director and staff of the Nigerian Institute for Trypanosomiasis Research, particularly J Adebote, S Idakwo, B Asha, I Nuhu, M Zakari, A Agwu, M Kura, A Oseni, and J Gadzama. The
Kaduna State Ministry of Health, local government areas and villagers in the trial area.

This work received support from WHO/UNDP/World Bank Special Programme for Research and Training on Tropical Diseases (Project ID Nos 870456 and 910553), the Leverhulme Trust, and Sightsavers (RCSB).

1 Wright WD. The characteristics of tritanopia. $\mathcal{F}$ Soc Am 1952;42:509-21.

Van Norren D, Went LN. New test for tritan defects evaluated in two surveys. Vis Res $1981 ; 21$ :1303-6.

3 Kalmus $\mathrm{H}$. The familial distribution of congenital tritanopia. Ann Hum Genet 1955:20:39-56.

Went LN, Pronk N. The genetics of tritan disturbances. Hum Genet 1985;69:255-62.

5 Henry GH, Cole BL, Nathans J. The inheritance of congenital tritanopia with the report of an extensive congenital tritanopia with the report of
pedigree. Ann Hum Genet 1964;27:219-31.
6 Weale RA. Age and the transmittance of the human crystalline lens. F Physiol 1988;395:577-87.

7 Verriest G, van Laetham J, Uvijls A. A new assessment of the normal ranges of the Farnsworth-Munsell 100 hue scores. Am 7 Ophthalmol 1982;93:635-42.

8 Krill AE, Smith VC, Pokorny J. Similarities between congenital tritan defects and dominant optic atrophy; coincidence or identity? f Opt Soc Am 1970;60:1132-9.

9 Gündüz K, Arden GB, Perry S, et al. Colour vision defects in ocular hypertension and glaucoma. Arch Ophthalmol 1988;106:929-35.

10 François J, Verriest G. Les dychromatopsies acquises. Ann Ocul (Paris) 1957;190:713-46.

11 Green FD, Ghafour JM, Allan D, et al. Colour vision of diabetics. Br F Ophthalmol 1985;69:533-6.

12 Birch J, Tertuik K, North F. Tritan screening with a modified TNO test. In: Verriest G, ed. Colour vision deficiences VIII. Dordrecht, Netherlands: Martinus Nijhoff/Dr W Junk Publishers 1987:227-32.

13 Birch J, Ariffin AE, Kurtz A. Colour vision screening for the detection of diabetic retinopathy. In: Drum B, Moreland JD, Serra A, eds. Colour vision deficiencies. Dordrecht, Netherlands: Kluwer Academic Publishers 1991:507-10.

14 Neuhann T, Kalmus H, Jaeger W. Ophthalmological findings in the tritans described by Wright and Kalmus. In: Verriest G, ed. Mod Probl Ophthalmol 17. Basle: Karger, 1976:135-42.

15 Abiose A, Jones BR, Cousens SN, et al. Reduction in incidence of optic nerve disease with annual ivermectin to control onchocerciasis. Lancet 1993;341:130-4

16 Abiose A, Murdoch I, Babalola O, et al. Distribution and aetiology of blindness and visual impairment in mesoendemic onchocercal communities, Kaduna State, Nigeria. Br F Ophthalmol 1994;78:8-13.

17 Murdoch I. The epidemiology of glaucoma and glaucoma related parameters in rural communities mesoendemic and nonendemic for onchocerciasis, Kaduna State, Northern Nigeria. MD thesis University of London 1993.

18 Birch J. In: Diagnosis of defective colour vision. Oxford: Oxford University Press, 1993: 84

19 Bird AC, El-Sheikh H, Anderson J, et al. Changes in visual function in the posterior segment of the eye during treatment of onchocerciasis with diethylcarbamazine citrate. Br F Ophthalmol 1980;64:191-200.

20 Murdoch I. People and eyes - statistical pitfalls in ophthalmology. MSc thesis. London: London School of Hygiene and Tropical Medicine, University of London, 1995.

21 Cousens SN, Yahaya H, Murdoch I, et al. Risk factors for optic nerve disease in communities mesoendemic for savannah onchocerciasis, Kaduna State, Nigeria. Trop Med Int Health 1997;2:89-98.

22 Wolf E, Kluxen G. Colour vision in a case of unilateral nuclear cataract. In: Verriest G, ed. Colour vision deficiences VII. The Hague: Dr W Junk Publishers 1984:343-8.

23 Cruz-Coke R, Varela A. Defective colour vision and alcoholism. Its association with colour blindness. Lancet 1966;ii: $1282-4$

24 Fialkow PJ, Thuline HC, Fenster CF. Lack of association between cirrhosis and the common types of colour blindness. N Engl F Med 1966;275:584-7.

25 Mäntyjärvi $M$. Observations on the use of the Lanthony Tritan Album. In: Drum B, Verriest G, eds. Colour deficiencies IX. Dordrecht: Kluwer Academic Publishers, 1989: 487-93.

26 Heron G, Erskine NA, Farquharson E, et al. Colour vision screening in glaucoma; the tritan album and other simple tests. Ophthal Physiol Opt 1994;14:233-8.

27 Murdoch I, Jones BR, Babalola OE, et al. Red dot card test of the para-central field as a screening test for optic nerve disease in onchocerciasis. Bull World Health Organ 1996;74: 573-6.

28 Birch J. Clinical use of a new pseudoisochromatic test for tritan colour deficiency. Optom Vis Sci 1993;70:30.

29 Birch J. In: Diagnosis of defective colour vision. Oxford: Oxford University Press, 1993:65-7 and 105-7. 